\title{
Biodanza in Healthcare Residences: Qualitative Study
}

\author{
Diletta Calamassi ${ }^{1}$, Angelo Palfrader ${ }^{2}$, Cristina Biagiotti ${ }^{3}$, Roberto Galli ${ }^{4}$ \\ ${ }^{1}$ AUSL Toscana Centro and University of Florence, Florence, Italy \\ ${ }^{2}$ Nursing Home Ojop Freinademetz, San Martino in Badia, Bolzano, Italy \\ ${ }^{3}$ Territorial Health Unit, Florence, Italy \\ ${ }^{4}$ AUSL Toscana Centro, Florence, Italy \\ Email: ^diletta.calamassi@gmail.com, angelopalfrader@virgilio.it,cristina.biagiotti@outlook.it,rgalli@hotmail.it
}

How to cite this paper: Calamassi, D. Palfrader, A., Biagiotti, C. and Galli, R. (2019) Biodanza in Healthcare Residences: Qualitative Study. Open Journal of Nursing, 9, 41-58.

https://doi.org/10.4236/ojn.2019.91005

Received: December 21, 2018

Accepted: January 18, 2019

Published: January 21, 2019

Copyright () 2019 by author(s) and Scientific Research Publishing Inc. This work is licensed under the Creative Commons Attribution International License (CC BY 4.0).

http://creativecommons.org/licenses/by/4.0/

(c) (i) Open Access

\begin{abstract}
Objective: Biodanza seems able to improve well-being and personal abilities and to prevent stress. This study's aim was to explore the experiences of the professional caregivers who participated in the Biodanza sessions. Materials and methods: The study which was carried out could be defined as a hermeneutic phenomenological study. In-depth and face-to-face interviews, as well as audio recording of professional caregivers who attended 24 sessions of Biodanza (12 sessions with only the professional caregivers and 12 sessions with patients with Alzheimer's disease), were used as methods to carry out the study. Subsequently, the interviews were transcripted and the narrative data were analyzed using the Giorgi method. Results: 6 Units of Meaning emerged (major topics) from the study: Feelings before the beginning of the sessions and during the Biodanza; Emotions during the sessions of Biodanza; The influence that the Biodanza experience had in the workplace; The impact of the Biodanza experience on personal life; The professional care givers' perceptions about the benefits of Biodanza on the patients; Organizational aspects for participation in the sessions of Biodanza. At first, Biodanza may cause embarrassment and initiating a kind of contact with each other may be difficult. Subsequently, positive emotions (such as energy and tranquility) arise in those who take part in Biodanza session. On the workplace, the subjects start having a better relationship with the colleagues who have also participated in the Biodanza sessions. They also feel less stressed during work and in private life as well. They feel like they're able to love and appreciate life more. Based on the caregivers' opinion, the patients also benefit from the Biodanza sessions. It's important to pay attention to the organization of the Biodanza sessions, in order not to cause discomfort to the operators during their daily work. Conclusions: The professional caregivers believe that Bio-
\end{abstract}


danza is helpful both on a personal level and in improving the relationship between people within the workgroup. The professional caregivers see improvements in the patients in regard to movement and deambulation, concentration, and aggression.

\section{Keywords}

Biodanza, Professional Caregivers, Qualitative Study

\section{Introduction}

Over the past few years, the personalized assistance given to clients with dementia has received increasing acclaim from medical institutions and within the care community. However, carrying out specific and innovative activities often represents a challenge.

A study from 2008 on people affected by dementia [1] pointed out that those that involved memory, music, and family, and that led to improvements in sensory stimulation were useful social activities. Other studies support the usefulness of these specific social activities in the perception of self-image [2], in socialization and solidarity [3] [4], in memory [5] and in the decrease of oppositional behaviours [6].

Some studies demonstrate that procedural memory and motor learning in dancers improve through dance [7] and similarly the preservation of memory and learning ability in persons with dementia improves after sessions of dancing [8] [9]. On this basis, a model of care was suggested in some care contexts, which included music and dance in order to support the residual abilities of the patients [10].

The music and elements of social interaction stimulated in the dance sessions seem to improve the mood and sensitivity of the participants, triggering positive memories associated with dance experiences from their youth, with the emotional content of the memories stimulating a beneficial effect on the memory [11].

The improvement of the efficacy of the interaction among the patients affected by dementia and the support personnel was found. These studies, in addition to confirming the beneficial effects of dance therapy sessions on the participants' attention, suggest an improvement in the job satisfaction of the professional caregivers and in their interaction with the patients [12] [13] [14] [15].

If used regularly, using dance in the treatment of elderly people with dementia results as a useful intervention, with an excellent cost-effectiveness [16]. From the point of view of professional caregivers, it seems to make interaction with the patients more pleasant [17].

Duignan et al.'s study claims that thanks to the dance sessions was a decrease in the agitation of the patients affected by dementia, an increase in the well-being 
of both patients and staff, with the development of a "therapeutic relationship" between them [15].

A literature review on the effects of "dance therapy" revealed both qualitative and quantitative studies, using different approaches (from therapeutic dance to physical exercise based on dance). The findings suggest that problematic behaviours decrease, while social interaction and well-being of both patients and the nursing staff improves [17].

It should be noted that there are different modalities to use music and dance within projects for treatment and care.

Substantial differences exist between dance and dance therapy and between dance therapy and Biodanza.

Biodanza was created in the sixties by Rolando Toro Araneda, a Chilean anthropologist, and psychologist and has been defined as a "system of human integration, of organic renewal, of affective rehabilitation and the re-learning of the original functions of life. Its methodology is to induce vivencia by means of music, singing, movement and group encounter situations" [18]. Participation in sessions of Biodanza intensifies the sense of self and encourages unconditional acceptance of the other people with whom one comes into contact (regardless of gender, ethnicity and health conditions), preventing the establishment of discriminatory attitudes and prejudices [19].

The vivencia [18], defined by Dilthey as "a lived instant", is an expression originating from the most intimate part of ourselves, even before symbolic or rational processing, and is induced by an ensemble of music and dances in an affective group [18].

Other than using music and dance, the vivencia is induced by contact and by the encounter and these elements differentiate it substantially from dance therapy.

The Biodanza exercises, with verbal communication reduced to a minimum, train the perception of emotions and states of mind, for listening to interiority, facilitating the activation of non-verbal communication. In addition to the perception of self, this method can increase attention and sensitivity to the surrounding environment by increasing the level of empathy [18]. Acting on a neurophysiological level, some studies suggest that Biodanza is effective in treating patients with fibromyalgia [13] [14].

In D'Alencar et al.'s study, the effects of Biodanza on a group of elderly people were investigated using the ethnographic method. The data was collected through semi-structured interviews and participant observation. For these seniors Biodanza represented a tool with which to face the difficulties related to their health, stimulating the change in behaviour following an increase in the vital impetus and of the will to live [20].

Gianelli's experiments led to the proposal of a course of Biodanza as a path for growth and personal development, to promote individual psychological well-being, to reduce the degree of alexithymia and the levels of stress [21].

A recent study [22] shows the positive effects of Biodanza in reducing stress 
and depression in Spanish students.

The purpose of this study is to explore the experience of the professional caregivers, who work in structures dedicated to the care of people affected by Alzheimer's Disease $(\mathrm{AD})$, who participated in a course of Biodanza.

\section{Patients and Methods}

\subsection{Study Design, Participants, and Steps Taken for the Implementation}

The study was a qualitative phenomenological type of study (hermeneutical phenomenology), accomplished by carrying out in-depth interviews with the professional caregivers who participated in multiple sessions of Biodanza within an independent project.

The people involved were the operations staff in the Alzheimer's Nucleus, specific Nuclei within Specialized Nursing Homes (SNF) for the care of persons affected by dementia, in two SNFs in Tuscany (Italy).

The following are the steps performed for the realization of the study:

1) Meeting with the leadership of the two SNFs for the approval of the study;

2) Meeting with the operational staff in the Alzheimer's Nucleus for explaining the study;

3) Obtaining consensus for the participation in the study;

4) Executing interviews addressed to professional caregivers for exploring their experience and analysis of narrative data.

\subsection{Modality of the Conduction of the Interviews and Narrative Data Analysis}

The interviews were conducted by a single interviewer. Before doing interviews, the researcher has suspended his knowledge and beliefs on about Biodanza (bracketing). The semi-structured interviews were conducted face to face and the audio was recorded in September 2016. The researcher asked the person to introduce him or herself, (warming-up and welcome phase) and to recount their own perceptions with respect to the experience concerning Biodanza (Open question). On the basis of the experienced that the respondent described and through questions posed by the researcher (Key questions), feelings, perceptions, and experiences were investigated. At the end of the interview, the researcher re-clarified aspects expressed by the person, in order to confirm the issues that were raised (Assessment of credibility). All audio recordings were transcribed onto a digital spreadsheet in Word format creating a separate document for each interview (Primary Documents).

The transcripts accurately reported some of the "narrative" that emerged during the interview.

Narrative data was analysed with the Giorgi method [23]. Each interview was fully read once, with the aim to understand all of them as a whole. This was followed by a second reading in order to comprehend the essence of the experience 
and identify the codes. Further readings helped locating by redundancy the Units of Meaning (main issues) and connecting the codes with the Units of Meaning. The Units of Meaning were linked between them, following a specific chronology: before the start of the Biodanza sessions, during the carrying out of the Biondanza session, after two months from the carrying out of the Biodanza sessions.

Three researchers individually read the interviews in their full version and they independently identified the key issues and the meaningful sentences that emerged. Successively the researchers compared notes in order to arrive at a single conceptualization of the transcripts.

The warming-up questions, the Open questions and the Key questions, are described in Table 1.

Once the study was done, those who took place in the experience, that "found" themselves in the researches' calculations, looked over the narrative data collected (member checking).

Once the study and the analysis of the narrative data were done, an external researcher confirmed the results (audit trial) by looking over the transcript and the elaborations.

The interviews were carried out in spaces within the SNFs involved. Each respondent had a bottle of water and a glass at their disposition. The interviews were conducted after obtaining informed consent.

\subsection{Characteristics of the Biodanza Sessions and the Modalities of Participation of the Interviewees}

During the Biodanza sessions, the participants are advised to suspend the use of speech in order to promote the experience of the music. In addition to the rule of silence, they are also asked to suspend judgment against their selves and others: There is also a rule of privacy (what any individual discloses cannot be divulged in any location).

In the first session, participants are invited to introduce themselves. The next 10 minutes are devoted to a brief explanation of the principles of Biodanza by the Certified Biodanza Operator ( $\mathrm{CBO}$ ). The $\mathrm{CBO}$ is qualified following of a theoretical-practical triennial (1050 hours) with standards defined by the International Biocentric Foundation, according to SRTA Biodanza System (Sistema Rolando Toro Araneda). Generally, the first part of the Biodanza session is dedicated to sharing, where the $\mathrm{CBO}$ calls on the group to freely express the

Table 1. Questions used in order to carry out the interview.

Warming-up questions $\begin{array}{r}\text { How old are you? How long have you been working in this place? } \\ \text { What's your occupation? } \\ \text { Biodanza... your experience... }\end{array}$
The patients did the Biodanza. In your opinion how did they live
this experience? Would you repeat the Biodanza experience?
Which are the improvement fields of Biodanza?


feelings, emotions, and thoughts that were generated during the previous session. After the group has expressed themselves, the $\mathrm{CBO}$ explains the objectives of the new session. The sessions all begin with an "activation phase", where the exercises and music encourage the integration of the group. The dances proposed work on motor and affective-motor integration. The basic exercises are a physiological walk, a coordinated walk in pairs, synchronized dances and games. The activation phase is followed by a "regressive phase" which stimulates the parasympathetic nervous system activity, promoting a connection to the self and perception of personal inner feeling. The second part of the session contains exercises like dances of fluidity and "eutony", encounters, embraces, caresses and cradle circles. This is followed by a "reactivation phase" which takes participants back to a neurophysiological state of activation similar to that of the beginning of the session.

In the independent project, two groups composed of eight practitioners (nurses, health workers, physiotherapists, psychomotor therapist, and professional educators) were created. Each group attended 12 sessions of Biodanza lasting two hours each and 12 sessions of Biodanza with the resident patients (8 patients for each of the two Alzheimer Nuclei), lasting one hour each (with a weekly frequency).

The 24 Biodanza sessions were conducted by a CBO and provided for the participation of another 2 people who had past experience of Biodanza (from November 2015 to April 2016).

The Biodanza sessions for the professional caregivers were held after their morning shift, after adjusting their working hours so as to allow for their participation on an on-going basis.

The sessions with patients and professional caregivers together were held in the mornings. In these sessions, there was no time provided for "sharing experiences", but only for a brief summary of what had been done in the previous session and a brief presentation of the current session. The patients were chosen randomly from the Alzheimer's nuclei of the two SNFs. The criterion for inclusion was determined by clinical diagnosis of $\mathrm{AD}$ and the values of the Mini Mental State Evaluation (MMSE) $\leq 24$.

The exercises and music (lasting up to 60 minutes), were calibrated by rhythm and length in relation to the characteristics of the patients (each patient was encouraged to express themselves with relation to their physical ability).

\section{Results}

In total 16 professional caregivers (14 women and 2 men), aged between 25 and 65 years were interviewed. The caregivers' professional figures were distributed as such: 1 nurse, 2 physiotherapists, 2 professional educators, 11 operators who had to take care of the basic assistance.

The working experience in the structure was variable: 4 years for the nurse, from 8 to 15 years for the Physical therapists, from 3 to 12 years for the opera- 
tors who had to take care of the basic assistance.

The caregivers decided to participate on a voluntary basis in the Biodanza Sessions and the interviews. The interviews lasted approximately 20 minutes.

6 Units of Meaning emerged (UM) and 15 related codes, creating 6 topics and 15 subtopics.

The first unity of meaning refers to the professionals' feelings before the start of the Biodanza sessions. The second unity of meaning refers to the feelings felt during the sessions (after overcoming the initial feel of embarrassment). The third and the fourth unity of meaning concern the Biodanza's influence on a personal and on a working level. The fifth concerns the patients' changes felt by the professionals following the Biodanza. The sixth refers to the impact felt by the professionals regarding the specific organizational aspects of the Biodanza sessions.

In general, the experience of Biodanza was experienced positively and produced beneficial effects on a personal level, within the workgroup and with relation to the patients.

A professional caregiver (physiotherapist) affirmed not having perceived improvements as a result of this experience, but he did not regret their participation. Overtime, he didn't notice any particular change on a personal level, but he stated that during the Biodanza exercises he felt a sense of well-being and tranquillity. His perception regarding the guests was however positive: he states that, in some cases, there was presence, interest, serenity. This professional expressed bewilderment regarding the possible effect overtime, as he believes, considering the pathology and his pluriannual experience, that only the effects related to "here \& now" can be considered realistic.

Following are the U.M. and codes, linked to the significant phrases that were directly reported by the participants.

\subsection{U.M. 1: Feelings before the Beginning of the Sessions and during the Path of the Biodanza Course}

Starting a course of Biodanza originates curiosity and willingness to experiment. Feelings of embarrassment may be present in the beginning, in that, like in many other contexts of relationships, we are exposing ourselves to others. In our society, contact with others, touching and being touched, is often experienced as invasive or being invaded and not as a fundamental element of the relationship. This UM unites 3 codes: Curiosity before the beginning of the experience; Initial embarrassment, Difficultly with "contact” during the first few sessions.

\subsubsection{Curiosity before the Beginning of the Experience}

The curiosity in approaching something unknown is a positive feeling which shows openness, availability, interest, courage.

We can consider curiosity as one of the elements which allow people to enrich themselves, to increase their experiences and knowledge.

Furthermore, enthusiasm, combined with curiosity, shows a strong motiva- 
tion to start a new experiential journey: “(...) I was very curious right from the beginning, when this course was proposed to me, I was intrigued so I wanted to try"; "(...) it was enthusiasm and curiosity to understand this".

\subsubsection{Initial Embarrassment}

When we change our surrounding context compared to the usual one (work, family, friends, etc.), the first sensation we feel is embarrassment, we feel "out of place", because we lose our certainties, anchored to points of reference that we know well and in which we move.

Moving in front of and with others, dancing, allowing our emotions to emerge, making them known to others in the "sharing" at the beginning of the Biodanza sessions, exposes us to others and can generate uncertainties, embarrassment: “(...) at the beginning a lot of embarrassment, as I was saying before, that we are not at all used to giving voice to our emotions"; “(...) even if I liked this thing about all dancing together, it made me a bit embarrassed, this fact of being able to touch colleagues".

\subsubsection{Difficulty "with Contact" during the First Sessions}

The distance of relationship/communication varies according to the ethnic, social and anthropological context.

Contact is a fundamental element in the mother-child relationship since birth: it is the expression of the confirmation of identity and the prior vehicle of affection.

As we become adults, in our society, contact becomes increasingly limited to the sphere of affective relationships and becomes marginal or even "unseemly" in the relationship/communication.

Think about the importance of the contact for the health professions, regarding the relationship with the assisted people. Gradually, but in an extremely natural way, in the Biodanza sessions, this difficulty disappears: "We felt a bit too close in amongst the people, at the beginning, it gave us this impression"; "(...) let's just say that at the beginning maybe we had some problems, we felt a bit invaded".

From the interviews what emerges is the embarrassment and difficulties with contact, which tends to disappear in subsequent sessions of Biodanza: “(...) this touching was a bit of an annoyance... after it was simpler"; “(...) the embarrassment kept diminishing until it became well-being, sincerely I also relaxed, especially in the end [session]...”.

\subsection{U.M. 2: Emotions during Sessions of Biodanza}

The vivencia, because of its characteristic, can cause positive energy sensations, develop emotions and help increase the well-being.

This UM unites 2 codes: The emerging energy, The emotions felt, and the improvements detected. Thanks to its characteristics, the vivencia may determinate sensations of positive energy, develop emotions and contribute to an increase of 
well-being:

\subsubsection{The Energy That Emerges}

Biodanza sessions are characterized by exercises, accompanied by music, which are intended to bring out, develop, and strengthen the well-being and personal potential, in order to foster a positive relationship with reality. The "affective group" is the container that favours and allows the expression of potentials: "(...) the fact of energy, that two people can exchange even only by holding each other's hands, caressing, the feeling of being in a group, all doing the same thing, you could just feel the energy, you transmitted energy"; "...I came out of this first session with a lot of positive energy, while I am usually always very hesitant, very negative...".

\subsubsection{The Emotions Felt, and the Improvements Detected}

What was expressed by the participants seems to confirm that Biodanza is a useful discipline to stimulate the joy of life, the vital impulse, the sensitivity to life, the affective and intimate communication, the awakening of pleasure, the connection to one's instincts, the creative and emotional expression through the body: "(...) I saw there was an immediate improvement, right there in the lesson"; “(...) Happiness (...)”; “(...) There was a mix of emotions, well-being”; "(...) It was an emotional experience because through free movements, you can begin to express yourself"; “(...) These sensations, of tears or of joy, must come out because I could see that if I could make them come out I felt better inside myself and feeling good in myself, I felt better with those around me"; "In the sensations I felt there were so much serenity and I felt like giving and receiving"; "(...) it brought me good memories and, above all, rekindled the emotions that I had not felt for a while, because it is an exchange of emotions anyway”; “(...) I felt good in that hour with them, because... I don't know... dancing all together, like that... this beautiful music, a feeling of well-being, of inner serenity".

\subsection{U.M. 3: The Influence of the Biodanza Experience in the Workplace}

In such a specific context, the increase in personal well-being can contribute to reducing work stress and to being more serene while undertaking work activities.

The Biodanza exercises can act on relationship/communication and on the capacity for contact, improving the climate internally.

This UM unites 2 codes: Reduction of work stress and greater tranquillity; Perceived change in the relationship between colleagues.

\subsubsection{Reduction of Work Stress and Greater Tranquillity}

In the UM and in the previous codes we have seen that the Biodanza exercises can allow everyone to find/improve balance, the inner harmony, a condition that generates a decrease of the negative effects of stress and allows to develop a feeling of tranquillity. 
Positive changes are perceived both at a personal level and at a group level. The result is a better understanding between the people, with positive effects also in the approach with the guests: “(...) In my opinion a decrease of stress... at least mine I also noticed more serenity in my co-workers"; “(...) In my opinion, there has been a decrease in the level of stress, because in the morning when you arrive and there are a hundred things to do you normally get caught up in anxiety... before it was like that, instead now you face things calmly, you deal them with one at a time and you still get to do them all and at the end of the morning you arrive more serene"; "(...) I think this technique can help, actually, you need a bit more, because it's something that is good for the caregivers like relaxing them, calming them... being calmer you can do your work better".

\subsubsection{Perceived Changes in the Relationships with Colleagues}

A working group that participates in Biodanza sessions can easily improve relationship/communication thanks to the sharing of the emotions that arise and the contact between the participants, which are aspects that favor the decrease of resistance and prejudices: "(...), in everyone generally, in fact, I noticed a different unity between everyone, more than anything else that I have noticed, we see each other in a different way"; "(...) and now instead we realized that it is more natural to be close, probably it was not so obvious in the group, we all knew each other but we had never embraced".

Only one professional caregiver (physiotherapist) did not perceive the effects on the workgroup: "I didn't see it as something usefuP", but he did not find any negative effects.

\subsection{U.M. 4: The Impact of the Biodanza Experience in Personal Life}

In this context, participants perceived changes on a personal level. Biodanza can be a path aimed at encouraging recovery, the development of the ability to bring out our instincts and to re-appropriate positive elements, such as the joy of life, the vital impulse and the sensitivity to life.

This UM unites 3 codes: Appreciating the beauty of life more; Finding tranquillity, Changes of character. Biodanza offers the opportunity for the positive energies of everyone to emerge, to appreciate the beauty of life. The possibility to generate well-being can induce the feelings associated with it.

\subsubsection{Appreciating the Beauty of Life More}

Biodanza exercises are aimed at developing our potential, both in the "activation" phase and in the "regression" phase.

They allow one to increase the capacity and sensitivity in grasping the small and big things that life offers them every day and to feel an intimate pleasure: “(...) Biodanza is a hymn to life, it's like becoming children again, it makes you rediscover the beauty of the day, of the night, at least to me that is, you see things a bit more rosy (...); “(...) before I went walking and it was the walking that did me good, but now I walk, I look at nature, I pause over a leaf, I pay more atten- 
tion to the small things, before I passed over things more, but now I pay a lot of attention to these things and I must say that I miss Biodanza".

\subsubsection{Finding Tranquillity}

We have previously seen how Biodanza can promote a reduction in work stress and improve the understanding in a working group. The recovery, the development of a condition of personal harmony, of tranquility, is transferred in a positive way also in the relationship with colleagues and with the working reality: “(...) I had been through a difficult year, I was very stressed (...), so I always had a stomach ache and lately I managed to overcome these moments of agitation more calmly"; “(...) it did me good (...) with Biodanza you can pull the plug, the problems at work and at home are less heavy"; "(...) it gave me more serenity".

\subsubsection{Change of Personality and Feelings}

The stimuli that each one receives through the Biodanza exercises are elaborated on a deep level and can favour positive changes in the relationship with ourselves and with the context in within we relate (family, affects, work environment, social relationships, etc.). They are also aimed at increasing the ability to listen to deep emotions on a personal level: “(...) it helped me a lot, maybe to accept the others a little more... and then I started to look for myself a little more"; “(...) it made me enter deep and then it made me discover the contrasts that I had inside of me and slowly, slowly these contrasts, step by step as I proceeded with the Biodanza lessons, were decreasing... it was a very positive thing for my growth"; "(...) Me, for the way I am made, I am a very idealistic person who tends to dream a lot of things and hardly ever finish anything, that is, my head is in the clouds... I am also not constant in the things I usually do generally... and instead I have seen with Biodanza that it has led me to be more constant in my things"; "(...) it also changes you on a character level, at least it was really good for me, because I was more agitated as a person and it gave me a lot of tranquillity, it calmed me a lot".

The same one professional caregiver (physiotherapist) said that they did not perceive any impact on themselves: "It was interesting, but it didn't leave me that much".

\subsection{U.M. 5: The Professional Caregivers' Perceptions regarding the Benefits of Biodanza on the Patients}

The caregivers expressed how the guests showed the effects that the Biodanza sessions, during their development, induced in their behavior. They also described what changes have occurred in the everyday life.

This UM brings together 3 codes: The improvements during the session; Changes after the experience, Concern that the benefits acquired during the Biodanza course will be lost.

\subsubsection{The Improvements during the Session}

The caregivers noted that the guests were involved and showed interest during 
the Biodanza sessions. Everyone has expressed it in a different way, through a smile, a more relaxed face, manifestations of joy, dancing, decreasing the rigidity in the movements, returning hugs, caresses and smiles: “(...) For what I saw there was an immediate improvement, right there in the lesson (...)"; "(...) it's a particular phase right now, they are very rigid, but when I was there, I saw that they smiled more than once, hummed while there was music..."; “(...) I saw the patients smiling in those moments, they collaborated"; “(...) Everyone reacted in their own way, some more than others (...)"; "They also participated in a fairly active way considering their conditions, so there those who were in wheelchairs and could not dance, but we saw that followed the music with their feet, so this means that they were present, or they even exchanged hugs, or returned kisses, like the caresses, that is to say, there was a real exchange"; "They had a lot of fun and I saw they were moved, I saw them actually participating".

\subsubsection{Changes after the Experience}

Most of the professional caregivers contend that the patients did demonstrate benefits after their participation in the Biodanza sessions. The perceived effects regard the improvement of movement and ambulation, concentration, the reduction of wandering and aggression:

"What was really striking for me was $S . T$., because as a person we had to really struggle with them lately just for ambulating, an exaggerated rigidity, even to get them out of bed was terrible, always stationary at the table with their eyes always closed (...) with Biodanza there was an interest in listening to this music, then they started to stand up, said their name repeatedly (...)"; “(...) We noticed especially with four of the patients that they are less anxious (...). They are more peaceful, they have less wandering (...); “(...) she has changed, she has started to be a little more focused, she was always in wandering and instead lately has tended to sit still, she manages to fold napkins...”; “(...) Even L. who in the morning would never get undressed to do hygiene, now let he lets himself be convinced more and more and his character is a little more softened, ..."; "(...) T. who is a patient at an advanced stage of the disease has an improved ambulation"; "(...) There is a certain person who attempted suicide many times, since we' ve done this course I see that they are already changed and are now happy to live"; "(...) a change happened with some people. In others less, but even with these there was a hint of a smile that wasn't there before, we noted this...".

The physiotherapist has not perceived improvements: “(...) beyond the immediate stimulus, there have been no major changes". This professional has expressed his concerns regarding the effects overtime of the Biodanza sessions on guests. They have not noticed major changes that, in his opinion, are linked to the extreme variability of the response to stimuli from people with Alzheimer.

\subsubsection{Concern That the Benefits Acquired during the Course of the Biodanza Will Be Lost/the Will and Necessity to Continue the Biodanza Course}

The majority of the professionals, also considering the phrases that report posi- 
tive effects, both on a personal level, as well as on a work group and on the guests, push for the utility and the need to continue the experience. Someone has even proposed the possibility of proposing the experience to the guests' families: "(...) he just loved Biodanza so much [referring to a patient], I mean all this physical contact, we could see it, because he hugged you close... but he needs it even now (...)"; “(...) now that we've started this project and now it has finished, we are wondering: 'what do we do now, what will happen?; "(...) at the time they were calm, you have to see then what will remain of these improvements. I mean for me, I would like to continue"; "(...) yes and I would continue if it were at all possible"; "It would be nice to let the various families try this experience, I think a bit for everyone... I see them, they feel important at that moment".

\subsection{U.M. 6: Organizational Aspects for Participation in the Sessions of Biodanza}

Most of the professional caregivers would have been available to participate in sessions of Biodanza both during their work shifts and in their free time.

This UM includes 2 codes: During work hours or "after hours"; The difficulties in the organization of workloads.

\subsubsection{During Work Hours and "off Duty"}

Some professional caregivers expressed difficulties related to the performance of routine activities when one or more colleagues were engaged in the Biodanza session.

"I would like it if it were during the work shift... that is, depending on the shift it would be great, but even if it was done in the morning and I had to start in the afternoon it would also be okay, because I have two hours off, I do Biodanza, I relax a little and then re-enter to work".

\subsubsection{The Difficulties of Organizing Workloads}

The operators clearly expressed some organizational difficulties related to the opportunity to optimally take part in the sessions with the guests. Their annotations addressed the difficulties for the guests and are nevertheless positive analysis elements to be submitted to the assessment of those responsible for the organization: "The problem for me I found was participating at that time, we are two colleagues on shift, plus a cleaning person, so if both of us were at Biodanza, only one person is left, therefore a difficulty (...)"; "Sincerely on an operational level it is difficult to manage the time, sometimes it happened that we did the Biodanza] during the work shift (...), in the afternoon it is easier [to participate], because most of the activities (lifting the patients, hygiene and everything else), are carried out in the morning"; "It is very difficult to do it in the morning, because you have to write the instructions, time is short, there is lunch and everything, therefore it is really complicated, especially if there are two of us and we both participate in the sessions together (...)".

The results are summarized in Figure 1. 


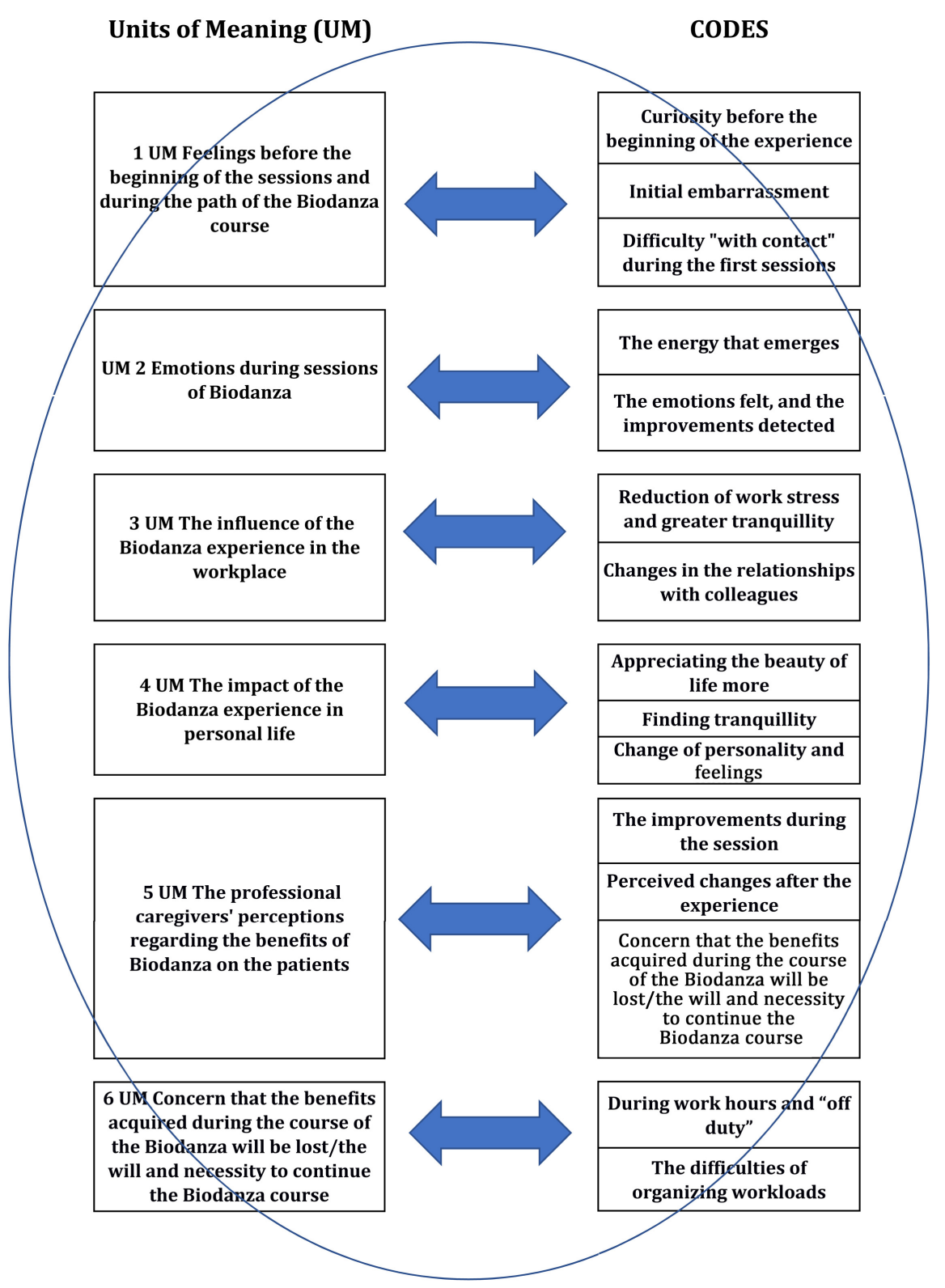

Figure 1. Summary of results.

\section{Discussion}

In the present study the assessment of the perceived effects of Biodanza was carried out in previously little explored context. Any some studies are those related to the effects of dance and dance therapy in people with dementia and also the effects of Biodanza in people with Fibromyalgia, and as they refer to specific contexts, they are difficult to compare.

In the present study, the experiences expressed by participants are divided over three clearly distinguished levels: individual effects, the effects in the workplace and the perceived effects on the patients.

Those who took part to the Biodanza sessions were moved by curiosity, which is an expression of the willingness to try, to experience something different and 
new.

Even if there are curiosity and willingness, initially the widespread feeling of embarrassment is linked to the beginning of a path in which movement, dance, and contact (caresses, hugs) expose one to others without barriers. Some participants clearly expressed the concept of "personal space", for which the gaze, the embraces, the kisses and the possibility to express their own emotions requires a gentle and gradual approach.

As the course progressed, the feeling of embarrassment gradually decreased until it disappeared, and this allowed the professional caregivers to freely express their emotions with their work colleagues. As in the studies analysed by Guzmán-García et al. in their research papers review [17], we can affirm that the individual well-being increased even in the professional caregivers. The professional caregivers reported a generalized sensation of calmness, serenity, of relaxation, a greater ability to accept others, and to be themselves.

During the sessions, some participants significantly perceived the feeling of positive energy determined by the exercises and the presence of an affective group.

As in the studies cited in the introduction [12] [13] [14] [15], also in terms of the working environment, positive changes have been verified.

As in studies present in the research papers [3] [4], in relation to the effects on the patients, the professional caregivers perceived a positive impact. The patients expressed a diffused serenity, fun, joy, and smiles. For some it was perceived as a resumption of contact with an external reality, a decrease of motor rigidity, of anxiety and wandering, a greater concentration also in the carrying out of simple activities and a decrease in incontinence.

In the professional caregivers, there is an awareness of the importance of continuity in the participation in the sessions of Biodanza for maintaining the positive effects on the patients. Reflections on the issues of participation in the sessions with the patients have been expressed, deriving from being simultaneously present in service and linked to the increase in workload for the few professional caregivers who remain with other patients and who do not participate in the Biodanza sessions.

Almost all professional caregivers have expressed the utmost willingness to repeat the experience of Biodanza and the wish to extend it to the relatives of the patients.

The vital emotions, of love and transcendence induced by Biodanza, create human closeness, solidarity, and empathy. The learning that takes place thanks to the vivencia, improves the communication skills of health workers because the experiencing of closeness and physical contact sensitizes them and makes them more aware. This awareness makes it possible to carry out gestures of assistance with greater capacity and attention in the helping relationship. The professional caregivers/patients "doing it together", in the classes of Biodanza, enhances the human dimension and breaks the patient-professional caregiver pat- 
tern made of distance, that characterizes being in a role.

While it is considered useful to include Biodanza as an activity for patients, family members and professional caregivers within an SNF, it is necessary to carefully evaluate the organizational aspects in order not to create operational inconveniences.

Biodanza is a bio-natural method that could also bring benefits in relation to the potential decrease in the use of drugs in people with AD.

The efficacy trials of Biodanza in the SNF are very limited, also in relation to the methodological challenges that must be faced in this type of research. We retain that further studies need to be done to gain more knowledge.

\section{Conclusions}

The subjects who participated in the Biodanza sessions had a positive experience. Biodanza has helped the participants in their work and in their private life.

In fact, Biodanza could be useful to reduce work stress and make relationships among colleagues better, but it could also be useful in order to gain a better vision on life and to change someone's personality and feelings.

These benefits would also have effects on patient care.

However, it is not possible to generalize the results due to the qualitative nature of the study.

\section{Ethical Aspects}

The subjects involved in the study participated voluntarily and before the beginning of the experimenting they were accurately informed about its development.

Before the start of the study, each subject has signed an informed consent.

The study respects the contents of the Helsinki declaration.

\section{Conflicts of Interest}

The authors declare absence of conflict of interest.

\section{Funding}

No funding was provided for this study.

\section{References}

[1] Harmer, B.J. and Orrell, M. (2008) What Is Meaningful Activity for People with Dementia Living in Care Homes? A Comparison of the Views of Older People with Dementia, Staff and Family Carers. Aging \& Mental Health, 12, 548-558. https://doi.org/10.1080/13607860802343019

[2] Bower, H.M. (1967) Sensory Stimulation and the Treatment of Senile Dementia. The Medical Journal of Australia, 1, 1113-1119.

[3] Lehner, S. (2006) Benevolent Ballet: Fall Prevention for the Elderly. $A D Q, 7,19-22$.

[4] Hayes, L. (2006) Line Dancing with Dementia. $A D Q, 7,31-34$.

[5] Coaten, R. (2001) Exploring Reminiscence through Dance and Movement. JDC, 9, 
19-22.

[6] Kindell, J. and Amans, D. (2003) Doing Things Differently: Dance in Dementia Care. JDC, 11, 18-20.

[7] Rösler, A., Seifritz, E., Krauchi, K., Spoerl, D., et al. (2002) Skill Learning in Patients with Moderate Alzheimer's Disease: A Prospective Pilot-Study of Waltz Lessons. International Journal of Geriatric Psychiatry, 17, 1155-1156. https://doi.org/10.1002/gps.705

[8] Fleischman, D.A., Wilson, R.S., Gabrieli, J.D., Schneider, J.A., et al. (2005) Implicit Memory and Alzheimer's Disease Neuropathology. Brain, 128, 2006-2015. https://doi.org/10.1093/brain/awh559

[9] Van Halteren-van Tilborg, I.A.D.A., Scherder, E.J.A. and Hulstijn, W. (2007) Motor-Skill Learning in Alzheimer's Disease: A Review with an Eye to the Clinical Practice. Neuropsychology Review, 17, 203-212. https://doi.org/10.1007/s11065-007-9030-1

[10] Harrison, B.E., Son, G.R., Kim, J. and Whall, A.L. (2007) Implicit Memory Preserved in Dementia: A Potential Model for Care. American Journal of Alzheimer's Disease, 22, 286-293. https://doi.org/10.1177/1533317507303761

[11] Kensinger, E. (2008) Emotional Memory across the Adult Lifespan. Psychology Press, Hoboken, 149-156.

[12] Palo-Bengtsson, L. and Ekman, S.L. (1997) Social Dancing in the Care of Persons with Dementia in a Nursing Home Setting: A Phenomenological Study. Scholarly Inquiry for Nursing Practice, 11, 101-118.

[13] Palo-Bengtsson, L. and Ekman, S.L. (2002) Emotional Response to Social Dancing and Walks in Persons with Dementia. American Journal of Alzheimer's Disease \& Other Dementias, 17, 149-153. https://doi.org/10.1177/153331750201700308

[14] Nyström, K. and Lauritzen, S.O. (2005) Expressive Bodies: Demented Persons' Communication in a Dance Therapy Context. Health, 9, 297-317. https://doi.org/10.1177/1363459305052902

[15] Duignan, D., Hedley, L. and Milverton, R. (2009) Exploring Dance as a Therapy for Symptoms and Social Interaction in a Dementia Care Unit. Nursing Times, 105, 19-22.

[16] Albanese, E., Banerjee, S., Dhanasire, S., Fernandez, J.-S., Ferri, C., et al. (2007) Dementia UK, A Full Report a Report into the Prevalence and Cost of Dementia Prepared by the Personal Social Services Research Unit (PSSRU) at the London School of Economics and the Institute of Psychiatry at King's College London, for the Alzheimer's Society. Alzheimer's Society, London.

[17] Guzmán-García, A., Hughes, J.C., James, I.A. and Rochester, L. (2013) Dancing as a Psychosocial Intervention in Care Homes: A Systematic Review of the Literature. International Journal of Geriatric Psychiatry, 28, 914-924. https://doi.org/10.1002/gps.3913

[18] Toro, R. and Matuk, E. (2007) Biodanza. Music, Movement, Expressive Communication for the Harmonious Development of Personality.

[19] Ghedin, E. (2016) Steps towards Happiness: The Value of Biodanza for Promoting Inclusion. Italian Journal of Special Education for Inclusion, 2, 189-206.

[20] D’Alencar, B.P., Mendes, M.M., Jorge, M.S. and Guimarães, J.M. (2008) Biodance as Process of Existential Renewal for the Elderly. Revista Brasileira de Enfermagem, 61, 608-614. https://doi.org/10.1590/S0034-71672008000500013

[21] Gianelli, M.T. (2015) Effectiveness on Health of an Annual Course of Biodanza, 
Health Psychology and 1-2015. Franco Angeli.

[22] López-Rodríguez, M.M., Baldrich-Rodríguez, I., Ruiz-Muelle, A., Cortés-Rodríguez, A.E., et al. (2017) Effects of Biodanza on Stress, Depression, and Sleep Quality in University Students. The Journal of Alternative and Complementary Medicine, 23, 558-565. https://doi.org/10.1089/acm.2016.0365

[23] Fain, A. (2004) Nursing Research, Read It, Understand It and Apply It. McGraw-Hill Education, New York, 221-226. 